\title{
Las representaciones sociales sobre el convenio PyME en la industria pesquera de Mar del Plata-Argentina: ¿Una salida posible para el blanqueo de los trabajadores marginalizados? (2014-2015)
}

Social Representations on SME Agreement in the fishing industry in Mar del Plata-Argentina: A possible outcome for the informal workers? (2014-2015)

María Soledad Schulze*

\begin{abstract}
Resumen: En 2007 tuvo lugar un nuevo conflicto laboral en el puerto de Mar del Plata (Pcia. de Buenos Aires/ Argentina). Durante los meses de lucha, lo que se reclamaba era la registración laboral bajo el convenio 161/75 de todos los obreros cooperativizados y/o que se encontraban trabajando en negro. Uno de los avances relativos luego del conflicto 2007 fue el convenio colectivo PyME, como anexo al 161/75. Tomando el caso específico de los trabajadores de la rama del filet de Mar del Plata, nos preguntamos sobre el juicio moral del conflicto 2007, el conocimiento de los avances relativos luego del conflicto y el juicio moral sobre el convenio PyME. Algunos resultados obtenidos nos indican que en este grupo de trabajadores prevalece un juicio moral negativo del conflicto 2007, lo cual estaría asociado al desconocimiento de los logros relativos alcanzados. Nuestro equipo de investigación realizó un total de 161 entrevistas durante diciembre de 2014 y julio de 2015, en una muestra de los trabajadores de la industria de procesamiento de pescado, de carácter no probabilístico, intencional por cuotas, definidas según los siguientes criterios conceptuales: tamaño de la empresa; ocupación concreta en la línea de producción y sexo.
\end{abstract}

Palabras clave: Conflicto, Puerto, Mar del Plata, Juicio Moral, Trabajadores, Argentina

\begin{abstract}
In 2007, a new labor dispute took place in the port of Mar del Plata (Province of Buenos Aires / Argentina). During the months of struggle, what was claimed was the labor registration under the agreement 161/75 of all cooperative workers and / or who were working in undeclared employment. One of the advances after the 2007 conflict was the PYME collective agreement, as an annex to $161 / 75$. Taking the specific case of the filet branch workers of Mar del Plata, we asked ourselves about the moral judgment regarding the 2007 conflict, the knowledge of the relative advances after the conflict and the moral judgment about the PYME agreement. Some results obtained indicate that in this group of workers a negative moral judgment of the 2007 conflict prevails, which would be associated to the ignorance of the relative achievements. Our research team made a total of 161 interviews during December 2014 and July 2015, in a non-probabilistic sample of workers of the fish processing industry, intentional by quota, defined according to the following conceptual aspects: size of the company; concrete occupation in the production line and sex.
\end{abstract}

Keywords: Conflict, Port, Mar del Plata, Moral Judgme, Workers, Argentina

Recibido: 8 noviembre 2018 Aceptado: 6 marzo 2019

\footnotetext{
* Argentina, Licenciada en Sociología Universidad Nacional de Mar del Plata y doctoranda en Ciencias Sociales y HumanasUniversidad Nacional de Quilmes. Becaria Doctoral CONICET-Docente Adjunta en la Universidad Nacional de la Patagonia San Juan Bosco (UNPSJB)-Puerto Madryn. Integrante del Instituto de Investigaciones Históricas y Sociales de la UNP y del grupo de estudios sociales y marítimos de la Universidad Nacional de Mar del Plata, schulzesoledad@yahoo.com.ar
} 


\section{Introducción}

Como cuestión relevante del análisis del orden social y cultural de las ciudades portuarias, nuestro equipo de investigación presenta un avance preliminar sobre algunos aspectos de la identidad moral, epistémica e ideológica de un universo de trabajadores de la industria de procesamiento de pescado de la ciudad puerto de Mar del Plata (Pcia. de Buenos Aires/ Argentina) ${ }^{1}$. Específicamente pretendemos explorar sus evaluaciones y concepciones ideológicas sobre los conflictos laborales que afectaron la rama de actividad en los últimos años, a partir de una concepción del proceso representativo que postula una relación entre la psicogénesis y la sociogénesis de conocimiento de los procesos sociales. La atracción se dirige a este grupo de trabajadores/as que histórica y generacionalmente ha sufrido los efectos devastadores de la precariedad y la flexibilización laboral en la rama del filet. En 2007 tuvo lugar un nuevo conflicto laboral en el puerto de Mar del Plata, donde se hicieron visibles las condiciones de precariedad profundizadas por las desigualdades en la estructura productiva y en la estructura ocupacional. Durante los meses de lucha, lo que se reclamaba era la registración laboral bajo el convenio 75 de todos los obreros cooperativizados y/o que se encontraban trabajando en negro. El conflicto de 2007, entre todos los conflictos que tuvieron lugar en el puerto, dio como resultado una nueva forma de contratación: el convenio PyME, como anexo al convenio 161/75. Tomando el caso específico de los trabajadores de la rama del filet de Mar del Plata, nos preguntamos sobre el juicio moral del conflicto del 2007, sobre el conocimiento o desconocimiento del avance relativo en materia de registración laboral luego del conflicto y el juicio moral sobre el convenio PyME.

Asimismo, nos preguntamos cuáles fueron los efectos de los procesos de pauperización laboral y social en los trabajadores de la rama del filet (de las clases subalternas) a nivel de la configuración de su identidad epistémica y moral, teniendo en consideración fundamental el conjunto de luchas colectivas que se llevaron a cabo a fines de los noventa y primera década de los dos mil para enfrentar la amenaza a sus chances de reproducción social. La hipótesis de la que aquí se parte es que los posicionamientos que ocupan los obreros en el mercado de trabajo, los trayectos laborales generacionales, los enfrentamientos, se relacionan con la construcción de representaciones sociales que definen la identidad. Es solo en un primer momento, que las ideas y las representaciones que los seres humanos tienen, aparecen ligadas con la actividad material.

Como bien es sabido a partir de los setenta la penetración del neoliberalismo produjo transformaciones que afectaron tanto a la estructura productiva nacional como al mundo del trabajo a ella asociada ${ }^{2}$. Las transformaciones sociales mencionadas fueron posibilitadas por el debilitamiento de las clases populares, las cuales en los noventa vieron amenazadas sus chances de reproducción social ${ }^{3}$. Una expresión de ese cambio desfavorable fue el incremento del trabajo precario en todas las actividades económicas, incluida la pesca. El rasgo característico de la precariedad laboral es la inestabilidad en la

\footnotetext{
1 Este avance de investigación procura articular con y enriquecer el Proyecto CONICET/UBACYT de la Dr. Muleras focalizado en el problema de la génesis representativa de procesos sociales complejos -como el poder y la justicia- en sectores populares de la Argentina contemporánea, a partir de un abordaje comparativo de fracciones trabajadoras diferenciadas en su carácter sociocupacional y en su identidad sociocultural. En tanto el trabajo investigativo de Muleras hasta el momento se ha centrado en el estudio de fracciones de trabajadores creyentes del Área Metropolitana de Buenos Aires, instalados en una concepción sacralizada del mundo (Muleras: 2013, 2008): el universo de devotos de San Cayetano.

2 Veáse Aspiazu, Daniel, y Khavisse, Miguel, La estructura de los mercados y la desindustrialización en la Argentina: 1976-1981. Buenos Aires, Editorial CET, 1983. Basualdo, Eduardo, Concentración y centralización del capital en la Argentina durante la década de los noventa. Una aproximación a través de la reestructuración económica y el comportamiento de los grupos económicos y los capitales extranjeros, Buenos Aires, Ediciones FLACSO, 2000. Cotarelo, Maria Celia, "La protesta en la Argentina de los 90", en Herramienta, No 12, Buenos Aires, 2000.

3 Ver Delfini, Marcelo, y Picchetti, Valentina, "Desigualdad y pobreza en Argentina en los noventa", en Politica y Cultura, $\mathrm{n}^{\circ} 24$, Buenos Aires, 2005, 187-206; y Svampa, Maristella, La Sociedad Excluyente. La Argentina bajo el signo del neoliberalismo, Buenos Aires, Taurus, 2005.
} 
relación salarial y su impacto negativo en la subjetividad de los trabajadores/as ${ }^{4}$.

En la industria pesquera marplatense la estrategia precarizadora de las empresas cristalizó en la formación y multiplicación de cooperativas fraudulentas. Esta salida empresarial busca la segmentación del mercado de trabajo, el cual se encontraba controlado sindicalmente por los fileteros/as y regulado por el CCT 161/75, logrando de esta forma menguar el poder obrero sobre dicho mercado. Mientas la empresa mantiene el planeamiento productivo, se deja a la pseudo-cooperativa la ejecución de la tarea de subcontratación. En lo que respecta a los montos salariales directos los distintos grupos de fileteros no perciben grandes diferencias, aunque sí lo hacen en ciertas condiciones de trabajo. En este sentido, es pertinente tener en cuenta que en los ' 90 las empresas locales experimentaron un crecimiento económico producto del incremento de sus exportaciones. Esto se debe a la sobreexplotación tanto de la mano de obra, como del principal recurso de la industria pesquera (merluza hubbsi). Según Colombo ${ }^{5}$, como los obreros pasaron de ser empleados de una empresa, a ser "socios" de una cooperativa, dejaron de pertenecer al gremio, lo cual hizo disminuir la influencia del sindicato para negociar en las paritarias mejores condiciones laborales y salariales. Ante los constantes reclamos que realizaban los fileteros 'cooperativizados', el sindicato en el 2007 gestiona con los empresarios un nuevo convenio de trabajo, el convenio PyME, que se anexaría al convenio 161/75. A partir de ahí se logró efectivizar bajo relación de dependencia a 2.133 fileteros, de los cuales el 83\% fue registrado bajo el convenio PyME. Si bien el convenio PyME es un contrato laboral que viene a introducir mejorías en la industria pesquera y aún hoy, en la pesca como en otras ramas de la economía nacional, hay un número importante de trabajadores/as sigue desarrollando sus actividades en condiciones de precariedad laboral.

Siguiendo a Pradas 6 , es posible afirmar que la precariedad laboral en la industria pesquera existió siempre, pero esta se profundizó en los noventa con la implementación de las cooperativas fraudulentas. Dicha precariedad se visibilizó a fines de los noventa, cuando los fileteros/as precarizados/as impulsaron diversas acciones colectivas contenciosas. La acumulación de agravios, luchas y experiencias organizativas motivó que una década más tarde, durante el año 2007, aquel grupo obrero lograra imponer la implementación de un nuevo marco legal de registración, el convenio PyME. Nos preguntamos si este último convenio representa el fin de un ciclo de agravios y luchas y una salida satisfactoria de aquella situación de precariedad laboral para los fileteros/as.

Nuestro equipo de investigación realizó un total de 161 entrevistas $^{7}$ durante diciembre de 2014 y julio de 2015, en una muestra de los trabajadores de la industria de procesamiento de pescado, de carácter no probabilístico, intencional por cuotas, definidas según los siguientes criterios conceptuales: tamaño de la empresa; ocupación concreta en la línea de producción y sexo. Se implementa en terreno una entrevista estructurada con preguntas de respuestas abiertas (características de las entrevistas clínicas y las entrevistas en profundidad) y de respuestas precodificadas (propias de las encuestas), de una hora de duración aproximada. Si bien los trabajadores fueron entrevistados entre siete y ocho años luego del conflicto del 2007, somos conscientes que al preguntarnos por las representaciones estamos analizando imágenes del pasado a partir del presente, imágenes del pasado que los trabajadores evocan, narran y recuerdan producto de haber vivido directa o indirectamente hechos de conflictividad. Sobre este punto, entendemos a la memoria colectiva como parte de los procesos sociales, como constitutiva de las prácticas sociales que pertenecen a un contexto. Es decir, que la memoria es una resultante de las relaciones sociales,

\footnotetext{
${ }^{4}$ Neffa, Julio, La crisis de la relación salarial: naturaleza y significado de la informalidad, los trabajos/empleos precarios y los no registrados, 2010, disponible en http://www.politicaspublicas.uncu.edu.ar/upload/1 crisisrelsalarial1.pdf

${ }^{5}$ Colombo, Guillermo y Contreras, Gustavo, "Repensando lo sindical en las luchas obreras. El caso de los trabajadores/as en la industria pesquera marplatense en dos momentos históricos: 1975 y 2000”, en Jornadas Universidad y Movimiento Obrero, Pasado y Presente del Mundo del Trabajo, Universidad Nacional de la Plata 8 y 9 de septiembre del 2006.

${ }^{6}$ Pradas, Eduardo, Un acercamiento a la problemática pesquera marplatense, Buenos Aires, ediciones El Mensajero, 2006.

${ }^{7}$ En el relevamiento en terreno participaron un total de veinte investigadores, becarios y estudiantes de la Universidad Nacional de Mar del Plata y de la Universidad de Buenos Aires.
} 
y como tal puede ser tomada como un archivo o depósito que brinda información que puede recuperarse . $^{\text {. }}$ Las representaciones son concebidas como construcciones o elaboraciones que dan cuenta de variados significados ante múltiples fenómenos de la vida social. Asimismo, lo que los trabajadores/as recuerdan es mucho más que la resultante de las experiencias, sino que a su vez es un producto interpretativo, un proceso inherente de los conjuntos sociales que se enmarca en procesos de socialización de los que nadie puede escapar

\section{Breve contextualización del conflicto del 2007}

Como objetivo/s explícito/s del conflicto laboral se pretendía lograr la registración laboral bajo el convenio 75 de todos los trabajadores/as que se encontraban trabajando en pseudo-cooperativas ${ }^{9} \mathrm{y} / \mathrm{o}$ que se encontraban trabajando sin registración laboral. El convenio colectivo de trabajo 161/75, que se implementa en 1975 para la rama del filet, es considerado por los trabajadores/as como una lucha ganada que estableció un conjunto de garantías laborales: un garantizado salarial, aguinaldo, vacaciones, asignación familiar, garantía horaria, entre otros.

Los trabajadores/as de la industria pesquera marplatense protagonizaron diversos hechos de protesta entre 1997 y el 2007, donde en especial se hicieron visibles las condiciones de precariedad profundizadas por las desigualdades en la estructura productiva y en la estructura ocupacional. La privatización de empresas públicas, los cambios en las legislaciones laborales orientadas a la flexibilización, la apertura comercial y financiera fueron el conjunto de políticas de Estado que caracterizaron la década del noventa. El resultado de estas políticas, como bien mencionamos anteriormente, fue una crisis de empleo inédita que se expresó en las altas tasas de desocupación a nivel nacional.

Fue en este contexto que algunos autores conjeturaron sobre la era del "fin del trabajo", o del fin de las sociedades salariales, como así también del colapso del llamado "Estado Benefactor" 10 . Sin embargo, a finales de los noventa comenzaron a constituirse escenarios donde el descontento y la disconformidad social se expresaron de múltiples formas: movilizaciones políticas y sociales, cortes de calles, carpas, manifestaciones callejeras, tomas de edificios públicos y privados, asambleas y ollas populares, actos públicos, piquetes, entre otras ${ }^{11}$. A partir de allí, desde las ciencias sociales comenzaron a elaborarse preguntas en torno a estos hechos y procesos de resistencia social organizada. Se interrogaron sobre la capacidad de "resistencia" de un sector de la sociedad que, en apariencia, durante los noventa

\footnotetext{
8 Visacovsky, Sergio E. (2004). "Entre lo evidentemente sucedido y lo posiblemente experimentado: para una reconciliación entre historia, memoria social y análisis narrativo". En Entrepasados. Revista de Historia, XIII, 26: 127-145.

${ }_{9}$ Diversas investigaciones coinciden en que las que las pseudo-cooperativas son las figuras que surgen en el marco de las búsquedas de salidas empresariales a la caída de la tasa de ganancia producida durante la crisis económica de mediados de los setenta. Estas salidas se relacionan con la posibilidad de romper el control que sobre el mercado de trabajo ejercían los trabajadores/as, segmentándolo para lograr de esta forma reestructurar el proceso de trabajo. De esta forma, la empresa mantiene el planeamiento productivo, dejando a la pseudo-cooperativa la ejecución de la tarea de subcontratación, predominando la organización científica del trabajo.

Para más detalle se pueden consultar las siguientes investigaciones:

Gennero de Rearte y otros, "Descentralización Productiva y Precarización Laboral: el caso de las cooperativas de fileteado de pescado", en Informe de Coyuntura, Centro de Estudios Bonaerense, 1997, Buenos Aires, 51 - 63 y Colombo, Guillermo; Nieto, Agustín y Mateo, José; Precarización y fraude laboral en la industria pesquera marplatense. El caso de las cooperativas de fileteado de pescado. Disponible en:

http://www.trabajo.gba.gov.ar/informacion/masse/categoriaA/13 MATEO Precarizacion y fraude laboral en la industria pesquera marplatense.pdf, Mar del Plata, 2010 (visto 29/4/2016).

${ }_{10}$ Mallimaci, Fortunato, "Crisis terminal, pobreza y sentidos en la Argentina contemporánea", en Theomai: Estudios sobre Sociedad, naturaleza y desarrollo, núm. 99, Buenos Aires, 2002.

11 Auyero, Javier, "Los cambios en el repertorio de la protesta social en la Argentina”, en Desarrollo Económico, Vol. 42, No. 166, Buenos Aires, 2002, 187-210.
} 
había perdido capacidad organizativa ${ }^{12}$.

Si bien la precariedad laboral en la industria pesquera existió siempre, se profundizó en los noventa con la implementación de las cooperativas fraudulentas ${ }^{13}$.

La impronta del sector pesquero en las manifestaciones de protesta no se redujo a aquellos años. El informe de SISMOS sobre conflictividad social hace observable que en el año 2012 un 57\% de las acciones fueron llevadas adelante por los asalariados/as, siendo los asalariados/as de las pesca los más activos con un $50 \%$ de acciones registradas (SISMOS, 2013) ${ }^{14}$.El descontento y la disconformidad social se expresaron de múltiples formas: movilizaciones políticas y sociales, cortes de calles, carpas, manifestaciones callejeras, tomas de edificios públicos y privados, asambleas y ollas populares, actos públicos, piquetes, entre otras.

Siguiendo a Nieto ${ }^{15}$, la negociación del convenio PyME luego del conflicto del 2007 implica reconstruir las correlaciones de fuerza entre el Sindicato y la Cámara del sector en sus distintas dimensiones: proceso de trabajo, recursos organizacionales, horizonte político. El convenio PyME en tanto modalidad en contratación de las fuerzas de trabajo sigue reproduciendo formas precarizadas de contratación laboral. Asimismo, luego del conflicto del 2007 muchos de los trabajadores/as fueron despedidos.

Respecto a los convenios colectivos de trabajo, tanto el convenio PyME como el Convenio 75 se definen como marcos legales destinados a regular las relaciones entre el capital y la fuerza de trabajo en los establecimientos dedicados al fileteado de merluza y otras variedades de pescado que se convienen o convengan en el futuro entre los empresarios y los trabajadores/as dedicados a limpieza y/o envasado de los mismos y los obreros fileteros/as, empaquetadoras/as, pesadores/as, peones y aprendices que realicen sus tareas típicas, así como otras actividades complementarias o accesorias que se llevan a cabo en las plantas de fileteado. El convenio PyME anexo al 161/75 se implementó a partir de 26 de junio del 2007, a los fines de ofrecer garantías laborales a los trabajadores/as de la rama industrial de procesamiento de filet. Sin embargo a pesar de ofrecer garantías laborales es un convenio que a diferencias del convenio 161/75 el convenio PyME extiende la jornada de trabajo, reduce los costos de la garantía salarial y aumenta los periodos de prueba, no tiene una garantía horaria ${ }^{16}$. Es decir, que el convenio PyME no supera ni iguala al convenio del 75 , pero de alguna manera ofrece mejores condiciones que las cooperativas, que directamente no cuentan con ninguna garantía laboral por más mínima que sea.

\footnotetext{
12 Iñigo Carrera, Nicolás. y Cotarelo, María, "Reestructuración productiva y formas de protesta social en la Argentina", en E. de la Garza Toledo (Ed.), Reestructuración productiva, mercado de trabajo y sindicatos en América Latina, Buenos Aires, Clacso, 2000.

13 Pradas, op. cit.

14 Para más detalles consúltese el "Informe sobre conflictividad social en Mar del Plata, Año 2012”, disponible en http://sismosmdp.wordpress.com/

15Nieto, Agustin, "Negociación colectiva y lucha de clases: Convenio laboral para fileterxs (1969-1970)", Anuario del Instituto de Historia Argentina, v.16, no 1, abril 2001 http://www.anuarioiha.fahce.unlp.edu.ar/

16 Respecto a la garantía horaria el convenio dice: Atento el carácter altamente perecedero de los productos a elaborar y que su ingreso a la planta no depende del proceso industrial a desarrollar, ni de la voluntad del empresario, sino de las capturas, condiciones meteorológicas y demás circunstancias que afectan a la actividad pesquera, las partes deciden estructurar una jornada de trabajo especial acorde a las características señaladas. Para ello se reconoce la facultad del empleador para distribuir la jornada de trabajo de manera desigual, asignando diariamente la cantidad de horas necesarias para procesar todo el pescado disponible en la planta, debiéndose asegurar a los trabajadores las pausas mínimas exigibles entre un día de trabajo y otro. Del mismo modo se reconoce como resorte exclusivo del empleador la determinación del horario de inicio de las labores y la diagramación de los días de trabajo durante la semana respectiva, contando con una flexibilidad de dos (2) horas para determinar el horario de inicio de las labores en el turno matutino y de una (1) hora para el vespertino posteriores a la fijada en la planilla. Será facultad exclusiva del empleador fijar el horario de planilla, el que no podrá ser anterior a las 05:00 A.M. horas. El empleador podrá convocar a trabajar antes del horario de planilla por razones de necesidad de servicio, aún antes de las 05:00 A.M. si lo considerara necesario. En ese caso el trabajo realizado en la hora inmediatamente anterior al horario de planilla será abonado con un recargo del 10\% y cuando se anticipara el ingreso en más de una hora el trabajo realizado desde el inicio de la labores hasta una hora inmediata anterior al horario de planilla será abonado con un recargo del 50\% (Ministerio de trabajo, empleo y seguridad social secretaria de trabajo; resolución $\left.\mathrm{N}^{\circ} 584 / 2007\right)$.
} 


\section{Juicio Moral sobre el convenio el conflicto 2007 y el convenio PyME ¿un convenio que trajo aparejado cambios positivos o negativos?}

Nos interesa conocer cómo juzga moralmente este universo de trabajadores portuarios el convenio PyME. En este sentido será de gran importancia conocer su posición ideológica frente a la lucha del 2007, así como los comportamientos individuales y colectivos que asumen: si aprueban o desaprueban desde el punto de vista moral el conflicto del 2007, y si conocen los avances relativos alcanzados luego del conflicto y a la atribución de responsabilidad de la conflictividad de la industria pesquera. A tales fines, instalamos en terreno las siguientes preguntas:

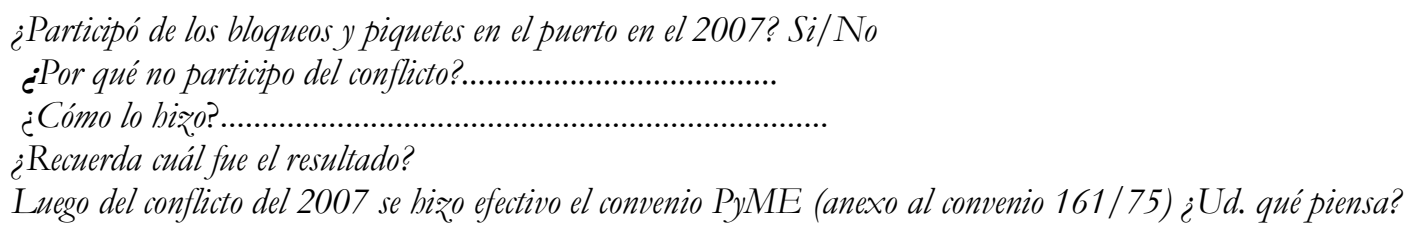

\section{A) Participación y Juicio moral sobre el conflicto 2007}

Respecto a los avances previos de esta investigación sobre el juicio moral sobre el conflicto del 2007, hasta aquí hemos podido observar que una proporción minoritaria de este grupo de trabajadores/as participa del conflicto del 2007. Dos tercios de los entrevistados no participaron del conflicto del 2007.

Cuadro I: Participación en el conflicto: (pregunta) ¿Participó de los bloqueos y piquetes en el puerto en el 2007? Si/No

\begin{tabular}{c|r|r|}
\hline ¿Participó del conflicto del 2007? & Frecuencia & $\begin{array}{c}\text { Porcentaje } \\
\text { válido }\end{array}$ \\
\hline No & 82 & $66 \%$ \\
\hline $\mathrm{Si}$ & 42 & $34 \%$ \\
\hline Total & 124 & 100 \\
\hline
\end{tabular}

Fuente: Elaboración Propia. Trabajadores de la Industria de procesamiento de pescado de la Ciudad Puerto de Mar del Plata/ Argentina. Años 2014 y 2015.

Asimismo, en trabajos previos nos hemos preguntado ¿cómo evalúan este grupo de entrevistados/as el conflicto laboral del 2007? ¿Consideran el conflicto laboral como algo positivo/negativo? Hasta aquí pudimos observar que este grupo de trabajadores evalúan la conflictividad del 2007 como un rasgo negativo de la historia de su rama de trabajo.

Cuadro II: Juicio Moral sobre el conflicto

\begin{tabular}{r|r|r|} 
Valorización del conflicto del 2007 & Frecuencia & $\begin{array}{c}\text { Porcentaje } \\
\text { válido }\end{array}$ \\
\hline Valorización Positiva & 47 & 37.9 \\
\cline { 2 - 3 } Valorización Negativa & 77 & 62.1 \\
\hline Total & 124 & 100 \\
\hline
\end{tabular}

Fuente: Elaboración Propia. Trabajadores de la Industria de procesamiento de pescado de la Ciudad Puerto de Mar del Plata/ Argentina. Años 2014 y 2015.

Adicionalmente, quienes no lo participan mayoritariamente justifican su falta de participación con una valorización negativa del conflicto sindical, es decir por no identificarse con las acciones y relaciones sociales que dan lugar a las medidas de fuerza de los trabajadores. Exploramos el juicio moral según la ocupación, según trabajen en cooperativas y empresas y por ultimo según sus trayectorias 
ocupacionales. Respecto a la ocupación el juicio negativo varía - aunque no sustantivamente - según las ocupaciones en la línea de producción, siendo los fileteros quienes en mayor medida valorizan positivamente la lucha sindical de los trabajadores.

Cuadro III: Ocupación/Juicio Moral sobre el conflicto laboral de 2007

\begin{tabular}{|c|c|c|c|c|}
\hline & \multirow{2}{*}{ OCUPACIÓN } & \multicolumn{2}{|c|}{$\begin{array}{l}\text { Juicio Moral sobre el Conflicto } \\
\text { del } 2007\end{array}$} & \multirow{2}{*}{ Total } \\
\hline & & $\begin{array}{l}\text { Valorización } \\
\text { Positiva }\end{array}$ & $\begin{array}{l}\text { Valorización } \\
\text { Negativa }\end{array}$ & \\
\hline & $\begin{array}{l}\text { Fileteado/procesamiento del } \\
\text { pescado }\end{array}$ & $\begin{array}{r}26 \\
48.10 \% \\
53.10 \%\end{array}$ & $\begin{array}{r}28 \\
51.90 \% \\
37.30 \%\end{array}$ & $\begin{array}{r}54 \\
100.00 \% \\
43.50 \%\end{array}$ \\
\hline & Envasado/calibrado/balanceo & $\begin{array}{l}33.30 \% \\
26.50 \%\end{array}$ & $\begin{array}{l}66.70 \% \\
34.70 \%\end{array}$ & $\begin{array}{r}100.00 \% \\
31.50 \%\end{array}$ \\
\hline & $\begin{array}{l}\text { Otras: } \\
\text { Emprolijado/despinado/peón }\end{array}$ & $\begin{array}{r}10 \\
32.30 \% \\
20.40 \%\end{array}$ & $\begin{array}{r}21 \\
67.70 \% \\
28.00 \%\end{array}$ & $\begin{array}{r}31 \\
100.00 \% \\
25.00 \%\end{array}$ \\
\hline Total & & $\begin{array}{r}39.50 \% \\
100.00 \%\end{array}$ & $\begin{array}{r}60.50 \% \\
100.00 \%\end{array}$ & $\begin{array}{l}100.00 \% \\
100.00 \%\end{array}$ \\
\hline
\end{tabular}

Fuente: Elaboración Propia. Trabajadores de la Industria de procesamiento de pescado de la Ciudad Puerto de Mar del Plata/ Argentina. Años 2014 y 2015

Es decir, que los fileteros tienen una valorización positiva de la protesta en un 48,1\%, siguiéndole con menor peso las envasadoras en un 33,3\%. Por su parte quienes tienen una valorización negativa se distribuyen de manera homogénea entre las ocupaciones. Mientras que el juicio moral positivo sobre el conflicto se incrementa en los fileteros alcanzando un 53\%. En síntesis, los fileteros incrementan la valorización positiva de la conflictividad en relación al resto de las ocupaciones de la industria de procesamiento de pescado.

CUADRO IV: Juicio Moral sobre el conflicto laboral de 2007/Con registración laboral - Sin registración laboral (según cooperativas, S.A)

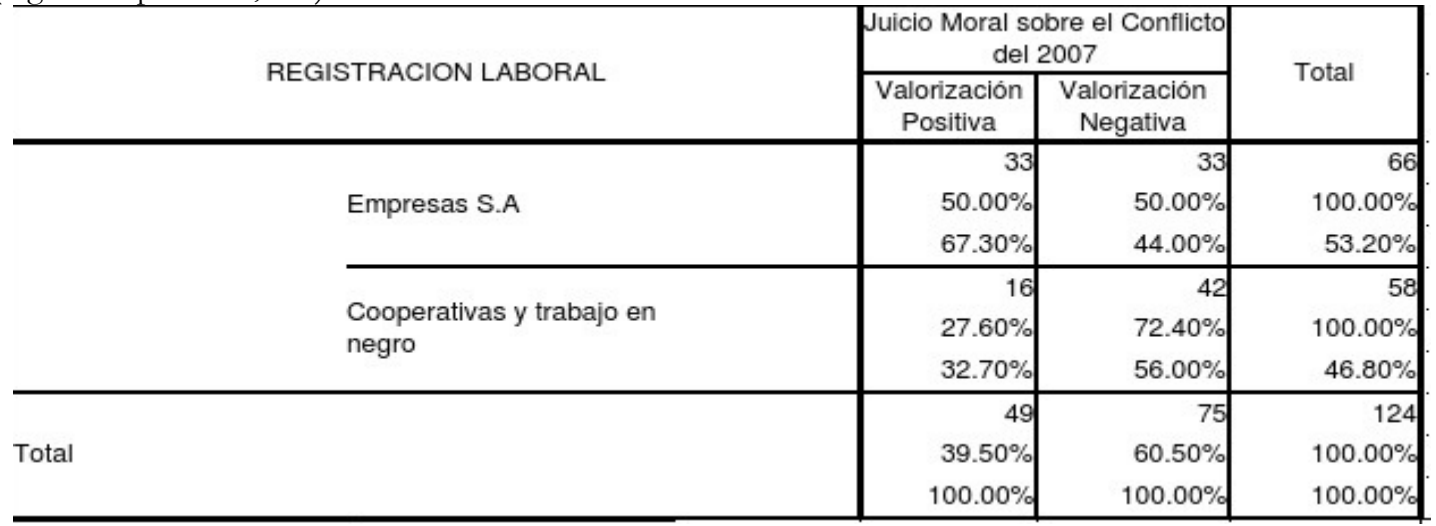

Fuente: Elaboración Propia. Trabajadores de la Industria de procesamiento de pescado de la Ciudad Puerto de Mar del Plata/ Argentina. Años 2014 y 2015 
Quienes no cuentan con registración laboral, es decir entre los trabajadores/as que están en peores condiciones, predomina con más de 20 puntos de diferencia una valorización negativa de la protesta social respecto al peso que esta asume en los trabajadores registrados (empresas S.A). Mientras que quienes tienen registración laboral se distribuyen homogéneamente en evaluar positiva y negativamente la protesta social. A la inversa se observa que en quienes pertenecen a empresas S.A se incrementa la valorización positiva del conflicto. De este modo, quienes valorizan negativamente la protesta, la participación en cooperativas o trabajo en negro alcanza el 56\%, en cambio, quienes valorizan positivamente la protesta social la participación en empleos con registración laboral (alcanza un 67,3\%). En suma, se observa una relación de correspondencia entre el juicio moral positivo y las mejores condiciones de inserción ocupacional según sea que pertenecen a cooperativas/ trabajo en negro o Empresas S.A. De lo anterior podemos pensar que la toma de la toma de conciencia y su expresión moral en la valoración positiva del conflicto del 2007 como medio legítimo de preservación de las condiciones sociales de vida de los trabajadores, se refuerza entre quienes tienen mejores condiciones relativas, y no a la inversa como podría suponerse desde una mirada que ignore la relación entre condiciones materiales de vida y grado de conocimiento.

CUADRO V: Historia Ocupacional y Juicio Moral

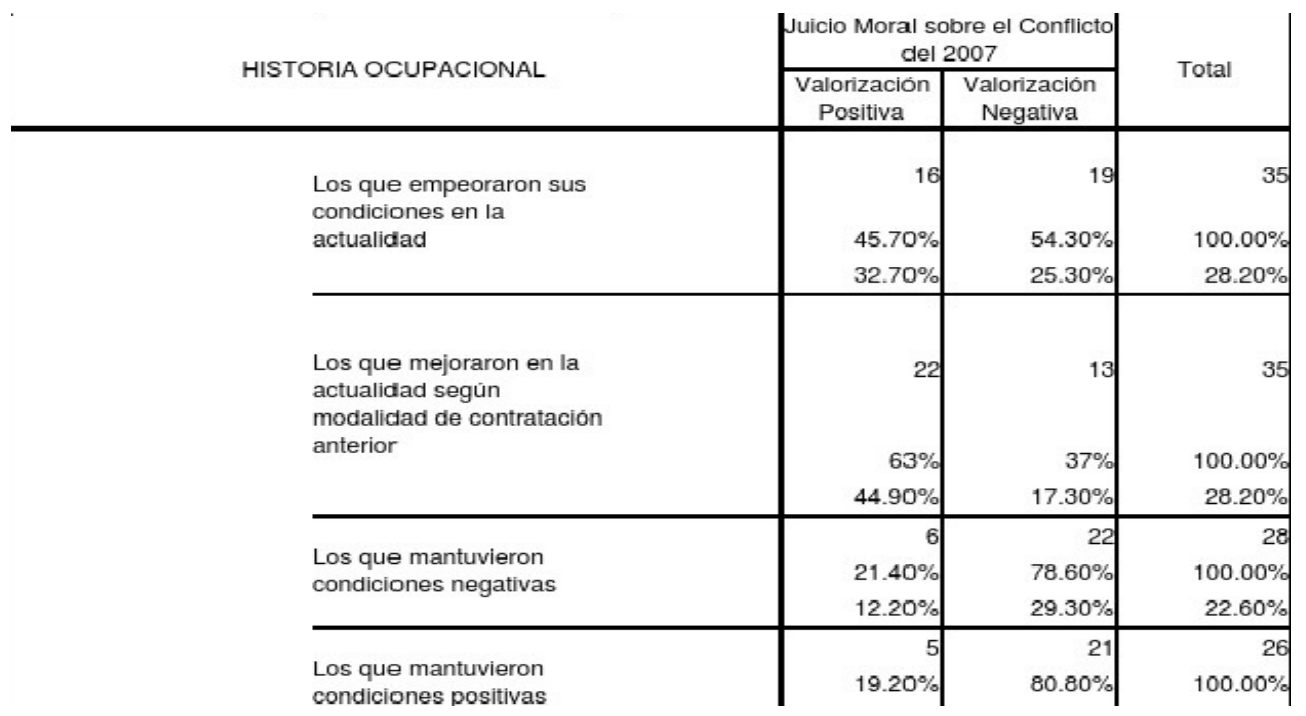

Fuente: Elaboración Propia. Trabajadores de la Industria de procesamiento de pescado de la Ciudad Puerto de Mar del Plata/ Argentina. Años 2014 y 2015

Lo que se observa es que entre aquellos que mantienen una inserción (ya sea porque han trabajado siempre con la misma registración laboral o siempre sin registración laboral), mayoritariamente expresan un juicio moral negativo sobre el conflicto del 2007. Es una diferencia significativa de casi 27 puntos con aquellos que vieron desmejorada su situación (54\%) y con quienes percibieron mejoras en sus inserciones (un 37\%). Es decir que aquellos que no sufrieron cambios y mantienen condiciones incrementan en treinta puntos el juicio moral negativo, respecto a quienes si cambiaron. Ahora bien, entre aquellos que mejoraron su situación prevalece un juicio moral positivo, $63 \%$, siguiéndole con una diferencia moderada aquellos que vieron precarizadas sus condiciones y valorizan positivamente en un $46 \%$ y una diferencia significativa con aquellos que han sostenido una misma inserción laboral positiva 
$(19 \%)$ o negativa (21\%) y juzgan positivamente el conflicto. De este modo es posible pensar que la valorización negativa se asocie a aquellas trayectorias que no han sufrido cambios en sus modos de contratación, indiferentemente mantengan condiciones positivas o negativas. Puede pensarse que estas identidades consideran que los conflictos laborales no son una salida para la transformación de sus propias condiciones de trabajo. En cambio, la valorización positiva de la conflictividad se asocia al cambio de la propia situación. Pero fundamentalmente, se incrementa en quienes el cambio ha significado una mejora o transformación positiva de sus condiciones laborales.

\section{B) Atribución de responsabilidad al conflicto de1 2007}

El hecho de que predomine una valorización negativa de los conflictos laborales, pero al mismo tiempo se reconozca que existe dicha conflictividad, hace que nos preguntemos, ¿a qué creen que se deba dicha conflictividad? En otras palabras: ¿quién es el responsable de que en la Industria Pesquera haya muchos conflictos sindicales-laborales? ¿A qué identidades sociales se atribuye la responsabilidad ante los variados conflictos laborales que se suceden en la industria pesquera de Mar del Plata? Los interrogantes para la variable atribución de responsabilidad: ¿Usted cree que la industria pesquera hay mucha conflictividad laboral? Si/No

¿Por qué?

Cuadro VI: Atribución de responsabilidad al conflicto del 2007

\begin{tabular}{|c|r|r|}
\hline Atribución de responsabilidad & Frecuencia & \multicolumn{2}{|c|}{$\begin{array}{c}\text { Porcentaje } \\
\text { válido }\end{array}$} \\
\hline $\begin{array}{c}\text { Por condiciones laborales, salariales falta de } \\
\text { derechos laborales }\end{array}$ & 68 & 43,0 \\
\hline Por falta de trabajo & 54 & 34,2 \\
\hline Por responsabilidad del trabajador & 20 & 12,7 \\
\hline No sabe/No atribuye responsabilidad & 16 & 10,1 \\
\hline Total & 158 & 100,0 \\
\hline
\end{tabular}

Como es posible observar, la principal atribución se registra entre quienes señalan problemas con los derechos y condiciones laborales- salariales, $43 \%$. Le siguen quienes señalan que el problema es la falta de trabajo $34,2 \%$, luego quienes adjudican la responsabilidad al trabajador, $12,7 \%$, y por ultimo quienes no atribuyen responsabilidad, 10,1\%. Del total de respuestas obtenidas es destacable que sea minoritario el grupo que atribuye la responsabilidad a los trabajadores, dado que este grupo de entrevistadxs está reconociendo factores ajenos a ellos mismos que provocan la conflictividad laboral. Es decir, la gran mayoría no piensan que son ellos los que generan o causan los conflictos, sino que el conflicto es la resultante de situaciones/circunstancias a las que están sometidos. De este modo decidimos pesquisar si hay relación entre el juicio moral y la atribución de responsabilidad. 
Cuadro VII: Atribución de responsabilidad y Juicio Moral

\begin{tabular}{|c|c|c|c|c|}
\hline \multirow{2}{*}{\multicolumn{2}{|c|}{ ATRIBUYEN RESPONSABILIDAD }} & \multicolumn{2}{|c|}{$\begin{array}{l}\text { Juicio Moral sobre el Conflicto } \\
\text { del } 2007 \\
\end{array}$} & \multirow{2}{*}{ Total } \\
\hline & & $\begin{array}{l}\text { Valorización } \\
\text { Positiva }\end{array}$ & $\begin{array}{l}\text { Valorización } \\
\text { Negativa }\end{array}$ & \\
\hline & $\begin{array}{l}\text { Por condiciones laborales, } \\
\text { salariales falta de derechos } \\
\text { laborales }\end{array}$ & $\begin{array}{r}27 \\
46.60 \% \\
55.10 \%\end{array}$ & $\begin{array}{r}31 \\
53.40 \% \\
41.90 \%\end{array}$ & $\begin{array}{r}58 \\
100.00 \% \\
47.20 \%\end{array}$ \\
\hline & Por falta de trabajo & $\begin{array}{r}16 \\
39.00 \% \\
32.70 \%\end{array}$ & $\begin{array}{r}25 \\
61.00 \% \\
33.80 \%\end{array}$ & $\begin{array}{r}41 \\
100.00 \% \\
33.30 \%\end{array}$ \\
\hline & $\begin{array}{l}\text { Por responsabilidad del } \\
\text { trabajador }\end{array}$ & $\begin{array}{r}5 \\
35.70 \% \\
10.20 \%\end{array}$ & $\begin{array}{l}64.30 \% \\
12.20 \%\end{array}$ & $\begin{array}{r}14 \\
100.00 \% \\
11.40 \%\end{array}$ \\
\hline & $\begin{array}{l}\text { No sabe/No atribuye } \\
\text { responsabilidad }\end{array}$ & $\begin{array}{r}10.00 \% \\
2.00 \%\end{array}$ & $\begin{array}{r}9 \\
90.00 \% \\
12.20 \%\end{array}$ & $\begin{array}{r}10 \\
100.00 \% \\
8.10 \%\end{array}$ \\
\hline Tota & & $\begin{array}{r}49 \\
39.80 \% \\
100.00 \%\end{array}$ & $\begin{array}{r}74 \\
60.20 \% \\
100.00 \%\end{array}$ & $\begin{array}{r}123 \\
100.00 \% \\
100.00 \%\end{array}$ \\
\hline
\end{tabular}

Fuente: Elaboración Propia. Trabajadores de la Industria de procesamiento de pescado de la Ciudad Puerto de Mar del Plata/ Argentina. Años 2014 y 2015

Como puede observarse, aquí también prevalece una valorización negativa de la conflictividad socio-laboral. Es decir, en todos los agrupamientos, más allá de la identidad a la que le atribuyan responsabilidad por el conflicto del 2007, predomina un juicio moral negativo sobre el conflicto.

Pero es significativo el hecho de la diversidad de factores a los que se atribuye la conflictividad según sea positiva o negativa la valoración de la misma. Quienes expresan un juicio moral positivo mayoritariamente (casi 60\%) lo atribuyen a las malas condiciones laborales y la falta de respeto a los derechos de los trabajadores. En cambio, entre quienes expresan un juicio negativo este factor cae veinte puntos.

Se observa una diferencia importante, dado que se incrementa 17 puntos la atribución de responsabilidad a la falta de derechos laborales en quienes tienen un juicio moral positivo sobre la conflictividad del 2007. Complementariamente quienes atribuyen la responsabilidad por la falta de derechos laborales, son quienes expresan una mayor proporción de juicios morales positivos sobre el conflicto.

En síntesis, el juicio moral negativo se incrementa entre quienes atribuyen la responsabilidad a los trabajadores o a la frecuente falta de trabajo en la actividad, mientras que el juicio moral positivo aumenta en quienes atribuyen la responsabilidad a la falta de derechos laborales y salariales.

\section{C) Conocimiento de los resultados del conflicto}

Otro aspecto a pesquisar era el conocimiento y el juicio moral que estos trabajadores tenían sobre los resultados obtenidos luego del conflicto del 2007. Es decir, nos preguntamos qué conocen como resultante del conflicto. Como bien mencionamos anteriormente, luego del conflicto del 2007 se hizo efectivo el convenio PyME como anexo al 161/75. También mencionamos que, si bien el convenio PyME se incluye como un modo más de contratación laboral para la rama de filete en la industria pesquera, es un convenio que presenta diferencias importantes con el convenio 161/75, dado que flexibiliza aspectos cruciales de los derechos laborales.

El primer paso con este indicador es poder identificar si conocen o no el resultado del conflicto, es decir, si identifican elementos objetivos que se hayan logrado luego de la lucha del 2007: aumentos 
salariales, efectivización/blanqueo, mejores condiciones de trabajo, etc. O si por el contrario no pueden identificar ningún elemento objetivo como resultado del conflicto.

Cuadro VIII: Conocimiento de los avances relativos del conflicto

\begin{tabular}{|c|r|r|}
\hline ¿Conoce cuál fue el resultado del 2007? & Frecuencia & $\begin{array}{c}\text { Porcentaje } \\
\text { válido }\end{array}$ \\
\hline No conoce/No sabe/ Falta de interés & 97 & 65,6 \\
\hline Conoce: localiza como resultado el convenio & 54 & 34,4 \\
PyME / Reconoce aumentos salariales, mejorías laborales & 151 & 100,0 \\
\hline Total & &
\end{tabular}

Dos tercios de nuestros entrevistados, un $65,6 \%$, no conoce los resultados/no sabe sobre los resultados obtenidos luego del conflicto. Un grupo minoritario, 34,4\% menciona, localiza alguno de los logros alcanzados. Luego de revisar dos indicadores sobre la identidad moral sobre el conflicto del 2007 y la identidad epistémica sobre los resultados de dicho conflicto nos preguntamos si hay alguna relación entre dicho juicio moral y el conocimiento/desconocimiento de los resultados.

CUADRO IX: Juicio moral sobre el conflicto del 2007/conocimiento-desconocimiento de los resultados

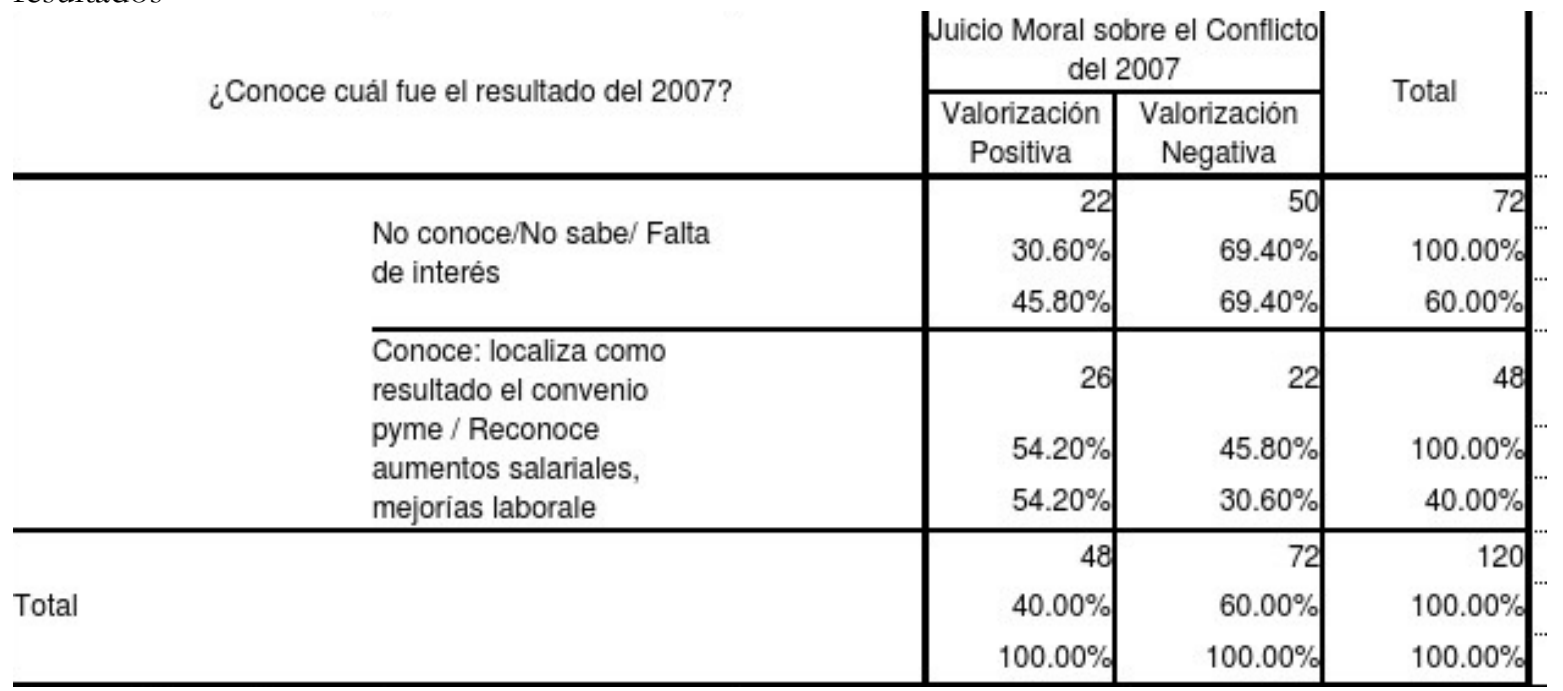

Fuente: Elaboración Propia. Trabajadores de la Industria de procesamiento de pescado de la Ciudad Puerto de Mar del Plata/ Argentina. Años 2014 y 2015

Existe una diferencia significativa de 26 puntos respecto al conocimiento/desconocimiento de los resultados y el juicio moral negativo sobre el conflicto. Específicamente se observa que quienes no conocen el resultado del conflicto 2007 , en un $72,2 \%$ tienen una valorización negativa del conflicto, en cambio para quienes conocen el resultado la valorización negativa desciende al 45\%. Ahora bien, entre quienes desconocen los resultados, valoriza positivamente el $27.8 \%$, y la valorización positiva se duplica, llegando al 54,2\%, entre quienes sí conocen los resultados.

En síntesis, la valorización positiva del conflicto del 2007 se asocia al conocimiento de los resultados $(56,5 \%)$ y contrariamente la valorización negativa del conflicto tiene correspondencia con el 
desconocimiento de los resultados del conflicto en un 70,3\%.

\section{D) Juicio moral sobre el convenio PyME}

Luego de pesquisar la evaluación moral general sobre el conflicto del 2007, la atribución de responsabilidad sobre la conflictividad en la industria y el grado de conocimiento sobre el resultado alcanzado en el 2007, le presentamos la siguiente pregunta a los entrevistados: (Luego del conflicto del 2007 se hizo efectivo el convenio PyME (anexo al convenio 161/75) ¿Ud. Qué piensa? Ante esta pregunta pudimos reconocer siete (7) grupos diferentes.

Cuadro X: Juicio Moral sobre el resultado del conflicto:

\begin{tabular}{|c|c|c|}
\hline $\begin{array}{l}\text { Luego del conflicto del } 2007 \text { se hizo efectivo el } \\
\text { convenio PyME (anexo al convenio 161/75) ¿Ud. Qué piensa? }\end{array}$ & ia Frecuenc & je $\quad$ Porcenta \\
\hline $\begin{array}{l}\text { Una valoración negativa/ localizan elementos que } \\
\text { precarizan su trabajo }\end{array}$ & 62 & 39,24 \\
\hline $\begin{array}{l}\text { Valorización Negativa: Entienden que es un convenio que } \\
\text { favorece a los empresarios }\end{array}$ & 16 & 10,12 \\
\hline Valorización negativa, no es como el 161/75 & 5 & $3,16 \%$ \\
\hline $\begin{array}{l}\text { No sabe/ no les interesa, no tiene un idea formada sobre } \\
\text { el PyME / No lo conocen por experiencia }\end{array}$ & 39 & 24,68 \\
\hline $\begin{array}{l}\text { Valorización positiva: Entienden que todo convenio sirve/ } \\
\text { no es ni bueno ni malo/ algunos le sirve a otros no por aplicarse de } \\
\text { igual manera }\end{array}$ & 7 & 4,43 \\
\hline $\begin{array}{l}\text { Valorización Positiva: Reconocen el convenio PyME como } \\
\text { favorable por las garantías laborales pero localizan diferencias } \\
\text { importantes con el convenio } 161 / 75\end{array}$ & 9 & 5,7 \\
\hline $\begin{array}{l}\text { Valorización positiva: Reconoces que es un convenio que } \\
\text { favoreció a muchos }\end{array}$ & 20 & 12,65 \\
\hline Total & 158 & $100 \%$ \\
\hline
\end{tabular}

Fuente: Elaboración Propia. Trabajadores de la Industria de procesamiento de pescado de la Ciudad Puerto de Mar del Plata/ Argentina. Años 2014 y 2015

Dando un paso más y con las características asumidas por estos grupos, agrupamos esta respuesta según sea el juicio moral positivo o negativo sobre el convenio PyME.

Una valoración negativa/ localizan elementos que precarizan su trabajo / localizan buenas condiciones en el 75 y no en el PyME, consideran que es un convenio que responde a los intereses del capital.

"Eso lo manejan los empresarios"

"No me gusta"

"Cuando se hizo el convenio vinimos a la cooperativa"

"Si es una porquería, no sé hasta dónde es bueno, por un lado, te quiere beneficiar a costa de sacarte por otro. A una envasadora no le sirve"

Valorización positiva: En este grupo incluimos a quienes consideran que es un convenio que 
favoreció a muchos, aunque algunos localizan diferencias sustanciales con el 161/75 y aquellos que evalúan que es bueno porque todo convenio sirve.

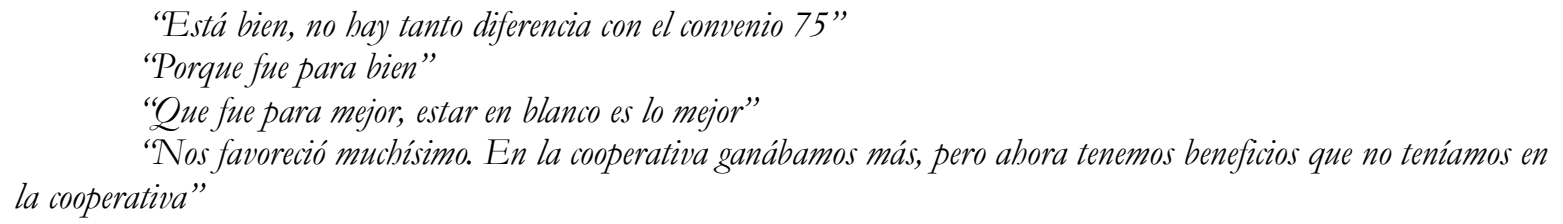

"Nos favoreció muchísimo. En la cooperativa ganábamos más, pero ahora tenemos beneficios que no teníamos en la cooperativa"

Cuadro XI: Juicio Moral sobre el convenio PYME

\begin{tabular}{|c|c|c|}
\hline Juicio moral sobre el convenio PYME & Frecuencia & $\begin{array}{l}\text { Porcentaje } \\
\text { válido }\end{array}$ \\
\hline $\begin{array}{l}\text { Una valoración negativa/ localizan elementos } \\
\text { que precarizan su trabajo / localizan buenas } \\
\text { condiciones en el } 75\end{array}$ & 83 & 50,0 \\
\hline $\begin{array}{l}\text { No sabe/ no les interesa, no tiene un idea } \\
\text { formada sobre el PyME / si conocen el } 75 \text { / no estaba } \\
\text { trabajando }\end{array}$ & 39 & 23,4 \\
\hline $\begin{array}{l}\text { Valorización positiva: entiende que es un } \\
\text { convenio que favoreció a muchos/ se logra la } \\
\text { efectivización / que está bien }\end{array}$ & 36 & 26,6 \\
\hline Total & 158 & 100,0 \\
\hline
\end{tabular}

Fuente: Elaboración Propia. Trabajadores de la Industria de procesamiento de pescado de la Ciudad Puerto de Mar del Plata/ Argentina. Años 2014 y 2015

De nuestros entrevistados/as el 50\% valoriza negativamente el convenio PyME, siguiéndole aquellos que, un 23,4\%, no saben/no les interesa/no tienen una idea formada del PyME, y por último quienes sostienen una valorización positiva $(27 \%$, ) dado que consideran es un convenio que favoreció a muchos. Por último, nos preguntamos sobre la relación entre el conocimiento/desconocimiento del resultado y el juicio moral sobre el convenio PyME. 
Cuadro XII: Conocimiento-desconocimiento de los resultados/juicio moral sobre el convenio PyME

\begin{tabular}{|c|c|c|c|c|}
\hline \multirow[b]{2}{*}{ 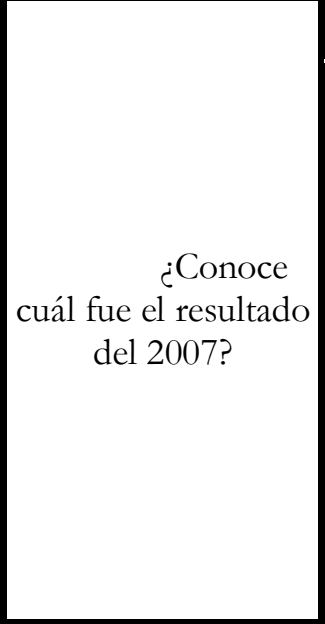 } & \multicolumn{3}{|c|}{ Juicio moral sobre el convenio PyME } & \multirow[b]{2}{*}{ Total } \\
\hline & $\begin{array}{c}\text { Una } \\
\text { valoración } \\
\text { negativa/ } \\
\text { localizan } \\
\text { elementos que } \\
\text { precarizan su } \\
\text { trabajo / } \\
\text { localizan buenas } \\
\text { condiciones en el } \\
75 \\
\end{array}$ & $\begin{array}{c}\text { No } \\
\text { sabe/ no les } \\
\text { interesa, no tiene } \\
\text { un idea formada } \\
\text { sobre el PyME / } \\
\text { si conocen el 75/ } \\
\text { no estaba } \\
\text { trabajando }\end{array}$ & $\begin{array}{c}\text { Valorización } \\
\text { positiva: Reconoces que } \\
\text { es un convenio que } \\
\text { favoreció a muchos/ se } \\
\text { logra la efectivización / } \\
\text { que está bien }\end{array}$ & \\
\hline \multirow{3}{*}{$\begin{array}{l}\text { No } \\
\text { conoce/No sabe/ } \\
\text { Falta de interés }\end{array}$} & 50 & 26 & 21 & 97 \\
\hline & $51,5 \%$ & $26,8 \%$ & $21,6 \%$ & $100,0 \%$ \\
\hline & $61,7 \%$ & $74,3 \%$ & $60,0 \%$ & $64,2 \%$ \\
\hline \multirow{7}{*}{$\begin{array}{l}\qquad \text { Conoce: } \\
\text { localiza como } \\
\text { resultado el } \\
\text { convenio PyME / } \\
\text { Reconoce } \\
\text { aumentos } \\
\text { salariales, mejorías } \\
\text { laborales }\end{array}$} & 31 & 9 & 14 & 54 \\
\hline & $57,4 \%$ & $16,7 \%$ & $25,9 \%$ & $100,0 \%$ \\
\hline & & & & $35,8 \%$ \\
\hline & & & & \\
\hline & & & & \\
\hline & & & & \\
\hline & & & & \\
\hline \multirow[t]{2}{*}{ Total } & 81 & 35 & 35 & 151 \\
\hline & $53,6 \%$ & $23,2 \%$ & $23,2 \%$ & $100,0 \%$ \\
\hline
\end{tabular}
del Plata/ Argentina. Años 2014 y 2015

La única diferencia significativa de la lectura de los datos surge entre aquellos que expresan desconocer el resultado y declaran no estar interesados en el convenio PyME. El grupo de trabajadores que dice no saber/no tener una idea formada sobre el PyME, en un 74,3\%, no conoce el resultado del conflicto. De este modo, el desinterés se asocia al desconocimiento: para valorizar algo hay que conocerlo. Adicionalmente los prejuicios morales obstaculizan el interés por el conocimiento, avanzar hacia el conocimiento. 


\section{Conclusiones}

Para poder emprender un análisis de las identidades morales y epistémica de los trabajadores/as del pescado, fue necesario conocer y analizar sus juicios morales sobre el conflicto del 2007, sobre el convenio PyME y el conocimiento o desconocimiento de los resultados alcanzados por el conflicto. Antes de avanzar en dicho sentido hemos intentado dejar en claro que los ciclos de luchas llevados adelante por los trabajadores/as se relacionan con la precariedad laboral y la flexibilización que se promueve en dicho mercado de trabajo.

Asimismo, a través de la caracterización del conflicto del 2007 se pudo observar cómo el despido de muchos trabajadores/as y la agudización de las malas condiciones de trabajo se constituyeron como las demandas y motivos que impulsaron un largo periodo de luchas, a partir de las cuales no sólo se visibilizaron las condiciones de precariedad de los trabajadores/as del pescado, sino que también se logró negociar en el 2007 un nuevo convenio colectivo de trabajo, el convenio PyME.

Para arribar al análisis propuesto hemos trabajando en el análisis de 161 entrevistas realizadas a trabajadores/as de la rama del filet. Hasta aquí hemos explorado los juicios morales sobre el conflicto del 2007, como así también sobre el conocimiento o desconocimiento del resultado de dicho conflicto. También nos preguntamos sobre la atribución de responsabilidad a la conflictividad en la industria pesquera y sobre el juicio moral acerca del convenio.

Respecto al análisis de los datos fue posible observar que una proporción minoritaria de este grupo de trabajadores/as participaron del conflicto, pero además quienes no lo hicieron justifican su falta de participación por tener una valorización negativa del conflicto social, es decir por no identificarse con las acciones y relaciones sociales que dan lugar a la conflictividad social. En este sentido vale remarcar que el juicio moral negativo se corresponde con que muchos de estos trabajadores/as se localizan por fuera del conflicto o atribuyen su falta de participación a no tener conciencia respecto de los derechos que se han perdido en la rama con la cooperatización de sus fuentes de trabajo. En este sentido, entendemos que uno de los problemas radica en que estos trabajadores/as son contratados bajo diversas figuras, lo cual no solo implica diferentes gradientes de precariedad laboral, sino también una manera de fragmentarlos, atomizarlos a los fines transformar esos cuerpos en algo útil y dócil ${ }^{17}$.

Los datos analizados sugieren la idea que el conflicto el 2007 no aparece como una herramienta posible de transformar el orden laboral establecido. Es decir, que existen trabajadores/as que señalan el carácter negativo que tiene la lucha y aquellas representaciones que localizan la acumulación de capital en el trabajo y el esfuerzo del propio capitalista, haciendo hincapié en la distribución de roles. Pero, además, indica la manera en la que la cosificación del individuo, lleva a que los asalariados se sientan en una posición demasiado débil para poder generar algún cambio del orden que rige el sistema laboral en el que están inmersos.

Asimismo, se hizo observable la correspondencia entre juicio moral positivo y conocimiento del conflicto/ del resultado. En nuestro grupo de entrevistados, más de la mitad expresa no conocer el resultado del conflicto y fue posible observar que la valorización positiva del conflicto se asocia al conocimiento de los resultados, e inversamente la valorización negativa tiene correspondencia con el desconocimiento de los resultados. Es decir, que aquellos trabajadores/as que dan cuenta de los logros y avances en términos de derechos laborales son quienes tienen algún grado de conciencia de lo que pasa en los conflictos que los atraviesan o involucran.

Otro aspecto a destacar es que uno de los supuestos que teníamos era que luego del conflicto del 2007, los trabajadores entendían que con esa lucha no se alcanzaron los resultados esperados, a partir de lo cual los entrevistados/as encontraron motivos para descreer en la organización y la lucha como

17 Ver, Foucault, Michel, Vigilary castigar. El nacimiento de la prisión, Buenos Aires, Ed. Siglo Veintiuno, 2008. 
herramientas para orientar posibles demandas y reclamos.

Respecto al juicio moral sobre el convenio PyME y el conocimiento/desconocimiento de los resultados, encontramos que aquellos que dicen no conocer los resultados expresan no estar interesados en dicho convenio. Podemos decir, luego de esta lectura que se observa asociación entre desinterés y desconocimiento. Por último, quisiera mencionar que la construcción de estos indicadores tiene como finalidad avanzar en este estudio exploratorio en términos de ver cómo se comportan los trabajadores/as a la hora de juzgar, evaluar y explicar diversas situaciones que hacen a sus condiciones de vida y al orden social en general. En este sentido nos interesa saber si este grupo de trabajadores se caracterizan por expresar una identidad de carácter más autónoma o más heterónoma, según sea el modo en que explican, evalúan y juzgan diversos aspectos vinculados al orden social.

\section{Bibliografía}

- Aspiazu, Daniel y Khavisse, Miguel (1983), La estructura de los mercados y la desindustrialización en la Argentina: 1976-1981. Buenos Aires, Editorial CET.

- Auyero, Javier (2002), "Los cambios en el repertorio de la protesta social en la Argentina", en Desarrollo Económico, Vol. 42, No. 166, pp. 187-210.

- Basualdo, Eduardo (2000), Concentración y centralización del capital en la Argentina durante la década de los noventa. Una aproximación a través de la reestructuración económica y el comportamiento de los grupos económicos y los capitales extranjeros, Buenos Aires, Ediciones FLACSO.

- Basualdo, Eduardo y Arceo, Enrique (2006), "Los cambios de los sectores dominantes en América Latina bajo el neoliberalismo. La problemática propuesta", en Neoliberalismo y sectores dominantes. Tendencias globales y experiencias nacionales. Buenos Aires, CLACSO.

- Colombo, Guillermo y Contreras, Gustavo (2006), "Repensando lo sindical en las luchas obreras. El caso de los trabajadores/as en la industria pesquera marplatense en dos momentos históricos: 1975 y 2000", en Jornadas Universidad y Movimiento Obrero, Pasado y Presente del Mundo del Trabajo, Universidad Nacional de la Plata 8 y 9 de septiembre del 2006.

- Colombo, Guillermo; Nieto, Agustín y Mateo, José, (2010), Precarización y fraude laboral en la industria pesquera marplatense. El caso de las cooperativas de fileteado de pescado. Disponible en: http://www.trabajo.gba.gov.ar/informacion/masse/categoriaA/13_MATEO_Precarizacion_y_fraude_ laboral_en_la_industria_pesquera_marplatense.pdf, Mar del Plata, (visto 22/4/2019).

- $\quad$ Cotarelo, María Celia (2000), "La protesta en la Argentina de los 90", en Herramienta, N 12.

- Delfini, Marcelo Fabián y Picchetti, Valentina (2005), "Desigualdad y pobreza en Argentina en los noventa", en Política y Cultura, Buenos Aires, nº 24, pp. 187-206.

- $\quad$ Foucault, Michel. (2008), Vigilar y castigar. El nacimiento de la prisión, Buenos Aires, Ed. Siglo Veintiuno.

- Foucault, Miechel. (2010), Defender la sociedad, Buenos Aires, Ed. Fondo de cultura económica.

- Gennero de Rearte y otros (1997), "Descentralización Productiva y Precarización Laboral: el caso de las cooperativas de fileteado de pescado", en Informe de Coyuntura, Centro de Estudios Bonaerense, Año $7, \mathrm{n}^{\mathrm{o}} 71$, pp. 51 a 63.

- Iñigo Carrera, Nicolás. y Cotarelo, María Celia (2000), "Reestructuración productiva y formas de protesta social en la Argentina”, en E. de la Garza Toledo (Ed.), Reestructuración productiva, mercado de trabajo y sindicatos en América Latina, Buenos Aires, Clacso.

- $\quad$ Iñigo Carrera, Nicolás (2004) La Estrategia de la Clase Obrera 1936, Buenos Aires, Madres de Plaza de Mayo.

- Iñigo Carreras, Nicolás (1996), "Los llamados cortes de ruta. Argentina 1993-1997, en PIMSA 1998, documentos de trabajo $\mathrm{N}^{\circ} 14$. 
- Maceira, Verónica (2009), "Segmentación de la fuerza de trabajo e identidad obrera en Argentina”. Disponible en Revista Mexicana de Sociología, n 3.

- Mallimaci, Fortunato (2002). 'Crisis terminal, pobreza y sentidos en la Argentina contemporánea', en Theomai: Estudios sobre Sociedad, naturaleza y desarrollo, núm. 99.

- Muleras, Edna (2008), Sacralización y desencantamiento. Las formas primarias del conocimiento del orden social, Buenos Aires, ed. Miño y Davila

- Nieto, Agustin, (2016), "Negociación colectiva y lucha de clases: Convenio laboral para fileterxs (1969-1970)", Anuario del Instituto de Historia Argentina, v.16, nº 1, http://www.anuarioiha.fahce.unlp.edu.ar/

- $\quad$ Pradas, Eduardo (2006), Un acercamiento a la problemática pesquera marplatense, Buenos Aires, ediciones El Mensajero. 